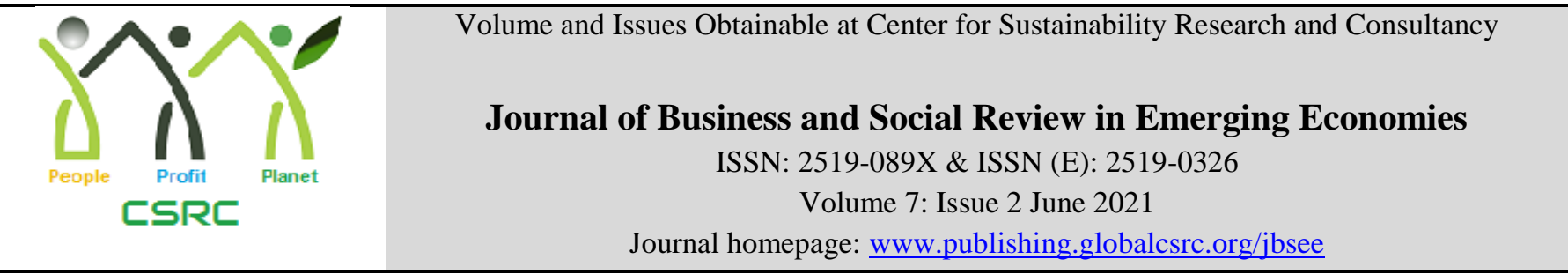

\title{
Gender Differences in Preferred Work Values in Pakistani IT Industry: Insights from Generation $\mathbf{Z}$
}

*Adnan Ahmad Khan, PhD Scholar, The Superior College, Lahore - Pakistan

Muhammad Ilyas, Associate Professor, Department of Economics, Govt. College Women University,

Sialkot, Pakistan

*Corresponding author's email address: adnan-khan@live.co.uk

ARTICLE DETAILS

History

Revised format: Feb 2021

Available Online: Mar 2021

\section{Keywords}

Generation Z,

Gender Differences,

Work Values,

Employability Attributes,

Gender Similarities

JEL Classification

M11, M12

\begin{abstract}
Purpose: Information Technology is playing a vital role in supporting struggling economies in the world and the Generation $\mathrm{Z}$ has the remarkable potential to make things happen in this context among all known cohorts. More than one third population of Pakistan falls in Generation $\mathrm{Z}$ and almost $48 \%$ of this pool comprises of females. Increasing trend in Pakistani females perusing higher studies and momentous enrollment of females at degree level implies that a significant chunk of available manpower for IT industry will be female in gender in upcoming years. IT industry has to pay attention to employability preferences of this pool as well in order to attract, attain and retain the best talented resources out of this segment to gain competitive advantage. Design/Methodology/Approach: This study is based upon a sample of IT students, approached through mixed sampling technique and gender-specific comparison is conducted with the help Mann-Whiney U test after ensuring reliability and validity checks. Findings: The results depict gender differences in almost $37 \%$ variables considered in this study, hence serve as a strong baseline for practitioners and strategists of IT industry in Pakistan to gain a competitive edge in ever-changing, dynamic business world. Implications/Originality/Value: Although handling of Generation Z representatives is a significant challenge for managers belonging to antecedent generations in current business operations, gender differences are yet another dimension to be explored in detail for competitiveness.
\end{abstract}

(C) 2021 The authors, under a Creative Commons AttributionNonCommercial 4.0

Recommended Citation: Khan, A. A., and Ilyas, M. (2021). Gender Differences in Preferred Work Values in Pakistani IT Industry: Insights from Generation Z. Journal of Business and Social Review in Emerging Economies, 7(1), 23-31

\section{Introduction}

Historians and psychologists divide the population into different generations as per their birth years because they demonstrate some internally shared, yet outwardly distinctive, believe and value systems. 
Generation $\mathrm{Z}$ is the latest recognized cohort as per the literature pertaining to generational studies, encompassing individuals born in the year 1995 or later (McCrindle, 2006). On the other hand, human psychology has been captivated since ages with the assumption that men and women have significant and undeniable personality differences (Hyde, 2014). These differences are both biological, as well as sociopsychological in nature. Assuming the pre-requisite of at least undergrad degree to start career in a professional field, the eldest representatives of Generation $\mathrm{Z}$ are most likely at the verge of completing their professional degrees or have just stepped into the job market at the maximum. It is an established fact that Generation $\mathrm{Z}$ have different attitude and contrasting mindset as compared to their predecessors, i.e. Millennials (Wiedmer, 2015), hence a comprehensive research is required to explore suitable amendments in organizational policies and structures to attract, hire and retain the best talent of this regiment. A little evidence is available in published research about preferred job choices of Generation $\mathrm{Z}$ as iGen'ers are just entering into the job market, the manifestations of studies pertaining to gender-based bifurcation of these preferences are even scarcer. The importance of exploring preferred employability attributes for Generation $\mathrm{Z}$ and gender differences in these preferences become multifold when it comes to Information Technology industry. This industry is very critical and making a significant contribution in economic growth of developed as well as developing countries (Shahiduzzaman \& Alam, 2014), though its impact is found more stronger in developed countries as compared to developing economies (Yousefi, 2011). In quest of exploring these critical elements in consolidation, this study aims to investigate the gender differences in preferred work values in ideal organizations among Generation Z students enrolled in Information Technology/Computer Science related professional degrees in Pakistan.

\section{Literature Review}

Prediction of potential behavioral outcomes of any group under observation is contingent on the consolidated exposure of demographic aspects to every single member of that particular cluster as every individual evaluates the situation as per the settings of his brought up and usually responds according to the same context (Angeline, 2011). Researchers like better to cluster the individuals with common demographic profiles for investigating any phenomena and so that they can generalize the findings for a specific segment of the society. Mannheim (1952) set the grounds for the concept of social generations by floated the idea of cohort aggregation based upon the similar experiences of individuals and impact of crucial incidents on their lifestyles, happened in their teenage years. Howe and Strauss (1991) even simplified it by specifying the standard range of social generations to 20 years' span. They further elaborated the root causes of shared believes and similar behaviors of members of any generation by linking them with the overall impact of PEST factors and critical incidents happened in their childhood. Observing the social behavior and shared believes of the members of any generation help the policymakers and strategists to predict some personal and professional characteristics of affiliates. Foster (2013) extended Mannheim's generational theory by incorporating thinking patterns, values and general psychological behavior towards the society together with biological birth era of participants.

The latest recognized generation is known as Generation Z, or iGeneration, has just entered in to the corporate arena. Generation $\mathrm{Z}$ has a sloppy initiation boundary - some researchers think it starts from 1993 (Statistics Canada, 2011), others suggest around 1996, several argue in 1982 and 1986 (Verhaagen, 2005; Tucker, 2006) but the year 1995 has found the wide-spread recognition (Singh, 2014; Twenge, 2018; Walvis, 2018; McGuire, 2019). Although it is a well-established and recognized generation in the research literature, this ambiguously agreed starting point refers to a decent overlap of features and characteristics among Generation $\mathrm{Z}$ and Millennials. Some of the critical incidents associated with the adolescence of this generation are the Oklahoma attack, bystanders in schoolyard crimes, a massive terror incident on Twin Towers and the series of post-9/11 counter-terrorism strikes globally (Allerton, 2001), environmental issues like global warming, extensive use of microchipped gadgets, and emergence of digital technologies (Singh, 2014). Use of internet and penetration of computing devices and IT enabled technologies in individual's lifestyle are the baselines for this generation (Kapil \& Roy, 2014). 
Work values can be described as the bunch of employment-related attributes considered intrinsically right by the jobseekers. Elaborating it further, workplace principles are the set of behaviors that personnel can presume in the organization and the norms adopted by colleagues to attain these behavioral standards (George \& Jones, 1999). Theory of Adjustment Layers defines job principles as combination of work components contributing in employees' job satisfaction (Dawis \& Lofquist, 1984). Jennifer Dose explained work principles as "Work values are interpretative criteria for job or workplace atmosphere through which people determine what may be 'correct' or evaluate the importance of preferences" (Dose, 1997). Generation $Z$ is assumed to be the most educated generation as compared to all of its antecedents (McCrindle, 2014), whereas revolution in the field of Information Technology has granted members of this cohort an easy access to multiple sources of information; hence these individuals have diversified experiences in life and varied ideologies, addictively attached with high-tech computing devices and gadgets (Mission \& Ministry, 2010). Being impeccable web nerds, they are naturally groomed for multitasking (Levickaite, 2010), avoid face-to-face interaction in corporate world, are generally poor in conflict management (Angeline, 2011) and admire formally established organizational structures. O'Malley (2006) found this generation more inclined towards temporary as compared to long-term employments opportunities, therefore breaks and timeouts help this generation regain their focus on official responsibilities. Other decisive work values for Generation $\mathrm{Z}$ for making job decisions are participation in decision making process (Csiszárik-Kocsír \& Garia-Fodor, 2018), job security (Meret et al., 2018), job roles aligned with personal interests (Arar \& Yuksel, 2015) and opportunities for professional development (Vecumniece \& Leontjeva, 2017). As this technological world is changing so rapidly, the affiliates of Generation $Z$ are found much focused on skill enhancement and self-learning to remain competitive. Importance of technological platform is self-explanatory for iGen'ers as technology is the distinctive factor for them, therefore communication channels within the organizations can boost productivity if aligned with Generation Z's preferences (Singh \& Dangmei, 2016). They like to be engaged with a mentor for their professional development (Bridges, 2015), appreciate flexible work arrangements, tend to hobble across multiple activities rapidly, emphasize more on efficiency than accuracy (Levickaite, 2010); hence strive for tolerance from the colleagues for their own convenience.

Existence of psychological gender differences and their impact in various walks of life are intriguing topics for researchers as well as for general public since ages. The instituting literature pertaining to scientific psychology has acknowledged gender differences even in late nineteenth century (Shields, 1975) whereas; many supporters of gender similarities do exist too (e.g. Thorndike, 1914; Hollingworth, 1918). Wendy Wood and Alice Eagly, although recognized the existence of biological differences between male and female human beings, theorized the existence and magnitude of psychological gender differences as a direct outcome of labor related restrictions/opportunities set for these segments in any society (Wood \& Eagly, 2012). Males, being stronger and bigger in size, favored historically for administrative, supervisory and gutsy roles whereas; females elected for nurturance being physically weaker and eventually ended up in subordination to dominating males (Hyde, 2014). Alice Eagly and his colleagues (1995) didn't found any significant gender difference in leadership effectiveness when they conducted series of meta-analyses on gender and effectiveness of leadership styles. While reviewing the 46 meta-analyses of research conducted on psychological gender differences, Janet Shibley Hyde (2005) found $78 \%$ of gender differences in psychological variables very small or even negligible. On the contrary, literature is enriched with evidences of gender differences as well. For example, Su and fellow researchers (2009) found males having more interest in material things whereas females having more interest in people in a meta-analysis of 47 interest inventories. As far as communication patterns are concerned, women found using more tag questions and tentative speech in conversations as compared to men (Tannen, 1990). Externalizing emotions (pride, anger, etc.) are found comprehensively associated with men and internalizing emotions (guilt, fear, embarrassment, anxiety, etc.) are dominantly associated with women (Durik et al, 2006). Men found demonstrating more helping behavior in dangerous situations in quest of achieving heroism, whereas women usually found expressing more concern in distressed situations (Eagly, 2009). Males tend to be engaged in physical aggression, whereas females have much more tendency to be aggressive verbally and relationally (Alink et al, 2006). These contradictory 
arguments are worth enough to investigate the gender similarities and differences in settings of this research study.

Information and Communication Technology can have a direct impact on economic growth of a nation either in the form of increased production of ICT enabled goods \& services or by adopting ICT to run the state's affairs, and can have an indirect impact by increasing multifactor productivity (MFP), a significant contributor in country's GDP (Jalaya \& Pohjola, 2002). However, impact of IT adoption would be more significant on economic development of a country as compared to increased production of ICT related products and services, East Asian countries are found more focused on production than adoption (Wong, 2002). Pakistan is an emerging economy; having $16.43 \%$ male and $15.31 \%$ female population in the age bracket of 10 to 24 years of age (Pakistan Bureau of Statistics, 2017a) which reflect the approximate concentration of Generation $\mathrm{Z}$ in the country. Female percentage is increasing slowly but steadily in acquiring undergraduate or above level education in Pakistan; from $0.47 \%$ to $1.21 \%$ in a span of twenty years (Pakistan Bureau of Statistics, 2017b). As per the enrollment statistics published by Higher Education Commission of Pakistan for 2017-18, all recognized Pakistani academic institutes have 33,827 female students enrolled in Bachelors level degrees with computing majors, representing $24.63 \%$ of total enrollment at that academic level. Similarly, 13,971 females were enrolled at Masters/MPhil levels comprising of $42.99 \%$ of total enrollment at this cadre. These significant figures of female population in Pakistan strongly demand the investigation of gender differences in local job market so that appropriate measures should be taken to engage them in playing their part in economic growth of the country.

\section{Research Design}

A structured questionnaire comprising of work values related variables, extracted from a PhD thesis titled An Empirical Study of the Characteristics of Generational Cohorts at Work (Murray, 2013) after examining through the lens of Generation Z's preferences, was designed in electronic form for this research study. The questionnaire encompasses Nineteen (19) work values related questions and 10 demographic questions in total. A mixed-method sampling approach was employed for this study, i.e. criteria (participants born in or after 1995, and completed or still enrolled in IT/CS related degree), convenience (the link of online questionnaire circulated through Facebook and emails) and snowball sampling technique (faculty members of various Computer Science departments were requested to forward the link to their students). This technique helped in collecting 284 responses suitable for statistically inquiring the research questions of this study. Except one work values related question, 5point Likert scale was used where $1=$ unimportant, $2=$ of little importance, $3=$ moderately important, $4=$ important and $5=$ very important.

SPSS 20.0 was used to perform various statistical analyses on the collected data. Content validity was ensured by getting instrument reviewed by two HR managers of software houses whereas Construct validity was confirmed with KMO measure of sample adequacy of 0.854 for 19 variables. Shapiro-Wilk's test of Normality confirmed that the data is significantly deviated from normal distribution, as significant values of all the variables were less than 0.05 , hence demanded a non-parametric test, Mann-Whitney $\mathrm{U}$ test, for comparing two gender-specific groups for Generation Z's preferred work values in IT industry of Pakistan.

\section{Findings of this Research Study}

Out of the total participants, $54.23 \%$ were males $(\mathrm{N}=154)$ and $45.77 \%$ were females $(\mathrm{N}=130)$. As far as status/role of participants is concerned, $7 \%$ were working professionals $(\mathrm{N}=20)$ and $93 \%$ were either studying or exploring a job to kick start their careers $(\mathrm{N}=264)$. A significant cohort of the participants were enrolled at Bachelors level $(74.30 \%, \mathrm{~N}=211)$ whereas least representation was observed at MPhil level $(3.53 \%, \mathrm{~N}=10)$. A detailed demographic analysis is presented in Table 1 below. 
Table 1: Demographic Details of Generation Z Participants

\begin{tabular}{|c|c|c|c|c|c|c|}
\hline Gender & Status & Intermediate & Bachelors & Masters & MPhil & Total \\
\hline \multirow{3}{*}{ Male } & Working Professional & & 10 & 4 & & \multirow{3}{*}{154} \\
\hline & Student or Job Seeker & 15 & 109 & 14 & 2 & \\
\hline & Total & 15 & 119 & 18 & 2 & \\
\hline \multirow{3}{*}{ Female } & Working Professional & 1 & 3 & 1 & 1 & \multirow{3}{*}{130} \\
\hline & Student or Job Seeker & 13 & 89 & 15 & 7 & \\
\hline & Total & 14 & 92 & 16 & 8 & \\
\hline
\end{tabular}

To explore the differences between both generations on these work values related variables, the results of Mann-Whitney U statistics (see Table 2) revealed that the preferences of male participants of Generation $\mathrm{Z}$ cohort differ significantly as compared to the female participants for education continuing opportunities $(\mathrm{U}=4739, \mathrm{p}<.05)$, intended time to spent with a particular employer $(\mathrm{U}=7749, \mathrm{p}<.05)$, incentives in terms of paid holidays $(\mathrm{U}=5808, \mathrm{p}<.05)$, implementation of technologically advanced communication channels in the organization $(\mathrm{U}=5861, \mathrm{p}<.05)$, presence of formal communication portal $(\mathrm{U}=5842, \mathrm{p}$ $<.05)$, perceived job security $(\mathrm{U}=6493, \mathrm{p}=.05)$ and tolerance level of colleagues for baring these participants' negligence's $(U=5285, \mathrm{p}<.05)$. No significant gender differences were observed for remaining 12 variables as significance values exceeded the acceptable threshold (i.e. $\mathrm{p}>.05$ ).

Table 2: Mann-Whitney U Statistics

\begin{tabular}{|l|c|c|}
\hline \multicolumn{1}{|c|}{ Attributes } & $\begin{array}{c}\text { Mann- } \\
\text { Whitney U }\end{array}$ & $\begin{array}{c}\text { Asymp. Sig. } \\
\text { (2-tailed) }\end{array}$ \\
\hline Training \& Development Programs & 5752.000 & .549 \\
\hline Career Advancement Opportunities & 5398.500 & .546 \\
\hline Technologically Advanced Company & 5755.000 & .626 \\
\hline Industry-Leading Company & 4875.000 & .278 \\
\hline Opportunities for Continuing Education & 4739.000 & .015 \\
\hline Tenure at One Organization & 7748.500 & .010 \\
\hline Clear Career Progression & 6163.000 & .068 \\
\hline Company Provided Gadgets & 6704.500 & .091 \\
\hline Family Support Benefits & 7483.500 & .709 \\
\hline Financial Benefits & 7244.000 & .708 \\
\hline Paid Time Off (Holidays) & 5808.000 & .009 \\
\hline Technologically Advanced Communication Channels & 5860.500 & .004 \\
\hline Implementation of Formal Communication Portal & 5842.000 & .008 \\
\hline Face to Face Interaction & 6659.000 & .087 \\
\hline Feedback Provision in Communication Channels & 6568.500 & .183 \\
\hline Being part of Management Team & 7476.000 & .943 \\
\hline Job Security & 6492.500 & .050 \\
\hline Job Role related to Personal Interests & 6593.000 & .194 \\
\hline Tolerance in Coworkers & 5285.000 & .005 \\
\hline
\end{tabular}

The in-depth analysis of participants' responses further revealed that females are more conscious about opportunities for further education whiling accepting/rejecting a job offer. Females are also found less interested in rapid job switches as $24.6 \%$ female participants expressed to stay with the same company for whole of their professional career whereas only $9.7 \%$ male participants expressed the same intentions. As 
far as the importance of employment benefits like paid holidays is concerned for Generation $\mathrm{Z}$ in considering a job opportunity, females found more interested in such incentives as compared to males as $30.5 \%$ male participants rated it from unimportant to moderately important while only $15.4 \%$ females rated such incentives that low. Technically advanced communication channels and formal communicational portals in an organization are found more attractive for males as compared to their counterparts as they headed up females by $63 \%$ vs $50 \%$ and $59.1 \%$ vs $44.6 \%$ respectively for rating these elements in important in their job hunt. iGener females are found less risk takers and more unsecure as compared to males as they expressed stronger concerns about job security and colleagues with higher tolerance level, however males too preferred secure jobs and tolerating coworkers but in lesser magnitude comparatively. Almost $49 \%$ females claimed it very important for their job hunt to have tolerating associates at potential employer whereas $39 \%$ males had the same desires.

No significance difference was observed between responses of male and female participants when asked about importance of Training \& Development programs $(\mathrm{U}=5752, \mathrm{p}>.05)$, Career Advancement opportunities $(\mathrm{U}=5398, \mathrm{p}>.05)$, being perceived as Technologically Advanced organization $(\mathrm{U}=5755$, $\mathrm{p}>.05)$ and reputation of the company as a Leading Brand of the industry $(U=4875, p>.05)$ in accepting a particular job or employer by these graduating students. Similarly, our data failed in identifying the varying behavior of both genders for contribution of assumed Clear Career Progression path $(\mathrm{U}=6163, \mathrm{p}>.05)$, impact of Company Provided Gadgets $(\mathrm{U}=6704, \mathrm{p}>.05)$, Family Support Benefits $(U=7483, p>.05)$ and Financial Benefits $(U=7244, p>.05)$ in taking a decision to accept an employment offer. The results couldn't confirm any gender difference for iGeners' preference for organizational culture appreciating face-to-face interaction between teammates $(U=6659, p>.05)$ and provisions of sharing/submitting feedback in adopted communication process $(U=6568, p>.05)$ in the organizations of their choice. As far as contingent rewards associated with dream jobs are concerned, Mann-Whitney U statistics rejected the presence of any significant deviation between both groups for being a part of management circles $(\mathrm{U}=7476, \mathrm{p}>.05)$ and alignment of job roles with jobseekers' personal interests $(U=6593, \mathrm{p}>.05)$.

\section{Conclusion, Limitations \& Directions for Future Research}

The observed gender specific differences can better be explained if reviewed in context of traditional dynamics of Pakistani society. Family structures in Pakistan demand females to take responsibilities of households and upbringing of kids. Contributing financially in quest of sharing load to meet family's routine expenses is still the biggest reason to allow females to work in this part of the world. Although the Generation $\mathrm{Z}$ is found more inclined towards temporary roles (O'Malley, 2006), the additional domestic duties of working Pakistani females justify their dominating desire for paid time-off. The tenth-rated public transit systems and unannounced social prohibition of riding bike/cycle or even sharing personal transportation by females in societies like Pakistan make it very excruciating for this gender to commute locally for any reason. Even though having a short-term engagement mindset, Generation $\mathrm{Z}$ do concern about job security (Meret et al., 2018) and financial protection (Kirchmayer \& Fratričová, 2017). The above discussed domestic characteristics of this society probably make females more prone to such threats which lead them to explore more stability in job and squeeze their courage to take risk for a career jump. Durik and fellow researchers (2006) labeled such threats as internalizing emotions and dominantly associated them with female gender. This also justifies their exploration of tolerating colleagues so that their mistakes and negligence could be ignored and covered by their fellow workers and would not create any threat for their jobs.

Generation Z, as a whole, is known as the most formally education generation among all the recognized generations mankind has seen till date (McCrindle, 2014) but extraordinary inclination of iGener females towards additional qualifications might be the consequences of these internalizing emotions. The building block of this generation is instituted on technological platform hence their desire of having advanced communication channels within the organization is quite natural. Women are generally found thorough communicators than men; they engage more tag questions and tend to be more sensitive in conversations 
(Tannen, 1990), this study seconds this stance convincingly. On the contrary, 63\% variables considered in this study failed in portraying significant difference between both genders hence these results support the arguments of researcher campaigning gender similarities (e.g. Eagly et al, 1995; Hyde, 2005).

Although it's an established fact that employment related attitudes significantly depend upon demographic elements, the current study has confirmed some gender differences in Generation Z's youngsters getting equipped to jump into the job market. A more comprehensive research by expanding the scope to all dimensions of Human Resource domain, focusing on multiple professions instead of Information Technology alone, taking a much bigger pool of respondents and convincingly partnering with the regulatory authorities can explore further insights of gender similarities and differences. Such comprehensive analysis will also raise confidence level of practitioners in adopting recommendations from the research outputs.

\section{References}

Alink, L. R. A., Mesman, J., van Zeijl, J., Stolk, M. N., Juffer, F., Koot, H. M., Bakermans-Kranenburg, M. J., \& van IJzendoorn, M. H. (2006). The Early Childhood Aggression Curve: Development of Physical Aggression in 10 to 50 Month Old Children. Child Development, 77(4), 954-966.

Allerton, H.E., (2001). Generation Why: They Promise to be the Biggest Influence since the Baby Boomers. Training \& Development, 55(11), 56-57.

Angeline, T. (2011). Managing Generational Diversity at the Workplace: Expectations and Perceptions of Different Generations of Employees. African Journal of Business Management, 5(2), 249-255.

Arar, T., \& Yüksel, İ. (2015). How to Manage Generation Z in Business Life. Journal of Global Economics, Management and Business Research, 4(4), 195-202.

Bridges, T. (2015, August 19). 5 Ways the Workplace Needs to Change to Get the Most Out of Generation Z. Fast Company. Retrieved from https://www.fastcompany.com/3049848/5-waysthe-workplace-needs-to-change-to-get-the-most-out-of-generation-Z

Csiszárik-Kocsír, Á., \& Garia-Fodor, M. (2018). Motivation Analysing and Preference System of Choosing a Workplace as Segmentation Criteria Based on a Country Wide Research Result Focus on Generation of Z. On-Line Journal Modelling the New Europe, 27, 67-85.

Dawis, R. V., \& Lofquist, L. H. (1984). A Psychological Theory of Work Adjustment: An IndividualDifferences Model and its Applications. University of Minnesota Press.

Dose, J. J., (1997). Work Values: An Integrative Framework and Illustrative Application to Organizational Socialization. Journal of Occupational and Organizational Psychology, 70(3), 219-240.

Durik, A. M., Hyde, J. S., Marks, A. C., Roy, A. L., Anaya, D., \& Schultz, G. (2006). Ethnicity and Gender Stereotypes of Emotion. Sex Roles, 54(7-8), 429-445.

Eagly, A. H. (2009). The His and Hers of Prosocial Behavior: An Examination of the Social Psychology of Gender. American Psychologist, 64(8), 644-658.

Eagly, A. H., Karau, S. J., \& Makhijani, M. G. (1995). Gender and the Effectiveness of Leaders: A MetaAnalysis. Psychological Bulletin, 117(1), 125-145.

Foster, K. (2013). Generation and Discourse in Working Life Stories. The British Journal of Sociology, 64(2), 195-215.

George, J. M., \& Jones, G. R. (1999). Understanding and Managing Organizational Behavior (3rd ed.). Addison-Wesley: New York.

Hollingworth, L. S. (1918). Comparison of the Sexes in Mental Traits. Psychological Bulletin, 15(12), 427-432.

Howe, N. \& Strauss, W., (1991). Generations: The History of America's Future, 1584 to 2069. New York: William Morrow \& Company.

Hyde, J. S. (2005). The Gender Similarities Hypothesis. American Psychologist, 60(6), 581-592.

Hyde, J. S. (2014). Gender Similarities and Differences. Annual Review of Psychology, 65, 373-398.

Jalava, J., \& Pohjola, M. (2002). Economic Growth in the New Economy: Evidence from Advanced Economies. Information Economics and Policy, 14(2), 189-210. 
Kapil, Y., \& Roy, A. (2014). Critical Evaluation of Generation Z at Workplaces. International Journal of Social Relevance \& Concern, 2, 10-11.

Kirchmayer, Z., \& Fratričová, J. (2020). On the Verge of Generation Z: Career Expectations of Current University Students. Education Excellence and Innovation Management through Vision, 15751583.

Levickaite, R. (2010). Generations X, Y, Z: How Social Networks form the Concept of the World Without Borders (the case of Lithuania). LIMES: Cultural Regionalistics, 3(2), 170-183.

Mannheim, K. (1952). Essays on the Sociology of Knowledge. London: Routledge \& Kegan Paul.

McCrindle, M. (2006). New Generations at Work: Attracting, Recruiting, Retraining and Training Generation $Y$. Norwest Business Park, New South Wales: McCrindle Research.

McCrindle, M. (2014). The ABC of XYZ: Understanding the Global Generations (3rd ed.), McCrindle Research, Bella Vista.

McGuire, P. (2019, March 5). Move Aside Millennials: Generation Z is set to Reshape the Workplace of the Future. The Irish Times.

Meret, C., Fioravanti, S., Iannotta, M., \& Gatti, M. (2018). The Digital Employee Experience: Discovering Generation Z. Digital Technology and Organizational Change, 241-256.

Murray, K. (2013). An Empirical Study of the Characteristics of Generational Cohorts at Work (PhD Thesis). Massey University - New Zealand.

O'Malley, S. (2006), Attracting and Retaining Generation Y Employees, Insurance Advocate, 117(24).

Pakistan Bureau of Statistics. (2017a). Percentage Distribution of Population by Age, Sex and Area. Retrieved from https://www.pbs.gov.pk/sites/default/files//Labour\%20Force/publications/lfs2017_18/TABLE3_perc_R.pdf

Pakistan Bureau of Statistics. (2017b). Percentage Distribution of Population by Age, Sex, Literacy and Level of Education. Retrieved from https://www.pbs.gov.pk/sites/default/files/Labour\%20Force/publications/lfs2017_18/TABLE3_perc_R.pdf

Shahiduzzaman, M., \& Alam, K. (2014). Information Technology and its Changing Roles to Economic Growth and Productivity in Australia. Telecommunications Policy, 38(2), 125-135.

Shields, S. (1975). Functionalism, Darwinism, and the Psychology of Women. American Psychologist, 30(7), 739-754.

Singh, A. (2014). Challenges and Issues of Generation Z. IOSR Journal of Business and Management, 16(7), 59-63.

Singh, A. P., \& Dangmei, J. (2016). Understanding the Generation Z: The Future Workforce. South-Asian Journal of Multidisciplinary Studies, 3(3), 1-5.

Statistics Canada. (2011). Census of Population.

Su, R., Rounds, J., \& Armstrong, P. I. (2009). Men and Things, Women and People: A Meta-Analysis of Sex Differences in Interests. Psychological Bulletin, 135(6), 859-884.

Tannen, D. (1990). You Just Don't Understand: Women and Men in Conversation. New York: Ballantine Books.

Thorndike, E.L. (1914). Educational Psychology (Vol. 3). New York: Teachers College, Columbia University.

Tucker, P. (2006). Teaching the Millennial Generation. The Futurist, 40(3), 7.

Twenge, J. (2018, November 13). Smartphones Raising a Mentally Fragile Generation. eNCA. Retrieved from https://www.enca.com/analysis/smartphones-raising-mentally-fragile-generation

Vecumniece, E., \& Leontjeva, O. (2017). Generation Z Business Students as Future Employees of Organisations in Latvia: Empirical Study. In 58th International Riga Technical University Scientific Conference on Economics and Entrepreneurship SCEE, 17, 131-132.

Verhaagen, D. A. (2005). Parenting the Millennial Generation: Guiding our Children Born between 1982 and 2000. Greenwood Publishing Group.

Walvis, A. (2018, September 17). Goldman Sachs | Insights - Millennials and Gen Z Picking Their Wardrobes Online. Goldman Sachs. Retrieved from 
https://www.goldmansachs.com/insights/pages/millennials-gen-z-pick-wardrobes-online.html

Wiedmer, T. (2015). Generations Do Differ: Best Practices in Leading Traditionalists, Boomers, and Generations X, Y, and Z. Delta Kappa Gamma Bulletin, 82(1), 51.

Wong, P.-K. (2002). ICT Production and Diffusion in Asia Digital Dividends or Digital Divide? Information Economics and Policy, 14(2), 167-187.

Wood, W., \& Eagly, A. H. (2012). Biosocial Construction of Sex Differences and Similarities in Behavior. In Advances in Experimental Social Psychology (Vol. 46, pp. 55-123). Academic Press.

Yousefi, A. (2011). The Impact of Information and Communication Technology on Economic Growth: Evidence from Developed and Developing Countries. Economics of Innovation and New Technology, 20(6), 581-596. 